\section{ACUTE HYDROCEPHALUS AND POSTERIOR REVERSIBLE ENCEPHALOPATHY SYNDROME (PRES) IN POSTPARTUM PERIOD: AN UNEXPECTED NEUROLOGICAL COMPLICATION}

\author{
Aisha Khan Jadoon ${ }^{1 \otimes}$, Saima Akhter'
}

\begin{abstract}
Hydrocephalus and Posterior Reversible Encephalopathy Syndrome (PRES) are under-diagnosed conditions in peri-partum period. As eclampsia mimics these conditions and it can mislead the clinician to an incorrect diagnosis causing potential morbidity and mortality.

A case of a 35 year old pregnant woman with seizures presented that was initially diagnosed as eclampsia but failure to regain consciousness post-delivery led to a multi disciplinary team formation and further investigation through Magnetic Resonance Imaging (MRI) that finally revealed communicating hydrocephalous and PRES. Prompt management was initiated by placing a Ventriculo-Peritoneal (VP) shunt resulting in full neurological recovery afterwards. As per author's knowledge there has not been a similar case reported as yet.
\end{abstract}

KEY WORDS: Posterior Reversible Encephalopathy Syndrome (Non MeSH); Hydrocephalus (MeSH); Ventriculoperitoneal Shunt (MeSH); Eclampsia (MeSH).

THIS ARTICLE MAY BE CITED AS: Jadoon AK, Akhter S. Acute hydrocephalus and posterior reversible encephalopathy syndrome (PRES) in postpartum period: an unexpected neurological complication. Khyber Med Univ J 2019; I2(2):I54-6. DOI: I0.35845/kmuj.2020.19804.

\section{INTRODUCTION}

$\mathrm{P}$ osterior Reversible Encephalopathy Syndrome (PRES) is an under-reported condition and associated with hypertension, renal and autoimmune diseases, sepsis, multi organ failure, organ transplantation and exposure to immuno-suppressants. Data from several studies have rendered eclampsia to be the most common cause of PRES. The cumulative global incidence of PRES is unknown. Hossain $\mathrm{N}$ et al from Karachi reported PRES prevalence to be $40 \%$ among eclamptic patients.'

Hydrocephalus is a rare complication of PRES and as per author's knowledge there are only a few studies present in the form of case reports but none that document co-existence of hydrocephalous and PRES in a gravid or postpartum patient.

\section{CASE REPORT}

A 35 year old female, with no known comorbids, attended the Emergency Department of Ziauddin University Hospital with one episode of tonic-clonic seizures, blurred vision and headache. She was 35 weeks pregnant. Immediate treatment with magnesium sulphate and diazepam was given and provisional diagnosis of eclampsia was made.

On detailed obstetric history, she was Gravida 4 and Para $\mathrm{I}^{+2}$. Previous parturition periods were uneventful. In the current pregnancy, she had regular antenatal visits and appropriate management of her pregnancy was done.

On examination she was agitated, semiconscious and only responded to painful stimuli. Blood pressure (BP) was 220/130 $\mathrm{mm} / \mathrm{Hg}$, pulse $180 / \mathrm{min}$, respiratory rate (RR) 60/min and oxygen saturation was $91 \%$ at room air. Her consciousness level kept fluctuating. Pupils were reactive to light bilaterally, no neck rigidity was found
I. Department of Medicine, Ziauddin University Hospital, Karachi, Pakistan. Email『: aishajadoon@hotmail.com Contact \# : +92-343-2287279

\section{Date Submitted:}

October II, 2019

Date Revised:

May 02, 2020

Date Accepted: May 05, 2020

and power was $5 / 5$ in all four limbs. Abdominal examination revealed that fetal movements were NIL and fetal heart sounds were audible but with difficulty. On vaginal examination, os was closed. Elective intubation was performed and patient underwent emergency caesarean section. Baby was healthy with a good APGAR score (Appearance, Pulse, Grimace, Activity, Respiration). Laboratory tests showed white blood cell (WBC) count of 31.1 , serum glutamic pyruvic transaminase (SGPT) of 58 and leukocytosis in the urinalysis but no proteinuria. Arterial blood gas (ABGs) analysis showed metabolic acidosis. Electrocardiogram (ECG) and chest $X$ rays were normal. Peri-operative treatment for blood pressure was achieved with intravenous labetolol. Her blood pressure remained well controlled afterwards and she was placed on regular anti-hypertensives for more precise BP control. Post operatively patient remained on ventilator because despite stopping all sedative medications and anesthesia she remained comatose for 48 hours.

On day three, physical examination showed bilaterally equal and reactive pupils, cranial nerves intact, no neck rigidity, power in the right arm and right leg was (0/5) and power in left upper and lower limb was $3 / 5$. She had alternate level of consciousness. Magnetic Resonance Imaging (MRI) of brain was performed that revealed moderate communicating hydrocephalous, water shed infarcts at bilateral parietal and left frontal regions as shown in Figure Ia and Ib. Radiological diagnosis of PRES related vasospasm was made.

Neurosurgeon advised surgery and patient underwent Ventriculo-Peritoneal (VP) Shunt placement on day 4 of admission. Conscious level dramatically improved after 36 hours of shunt placement. Blood Pressure was 130/76 $\mathrm{mm} / \mathrm{Hg}$, Pulse $80 / \mathrm{min}, \mathrm{RR} 18 / \mathrm{min}$ and Oxygen saturation was $99 \%$ at room air. Pupils were reactive to light bilaterally, 


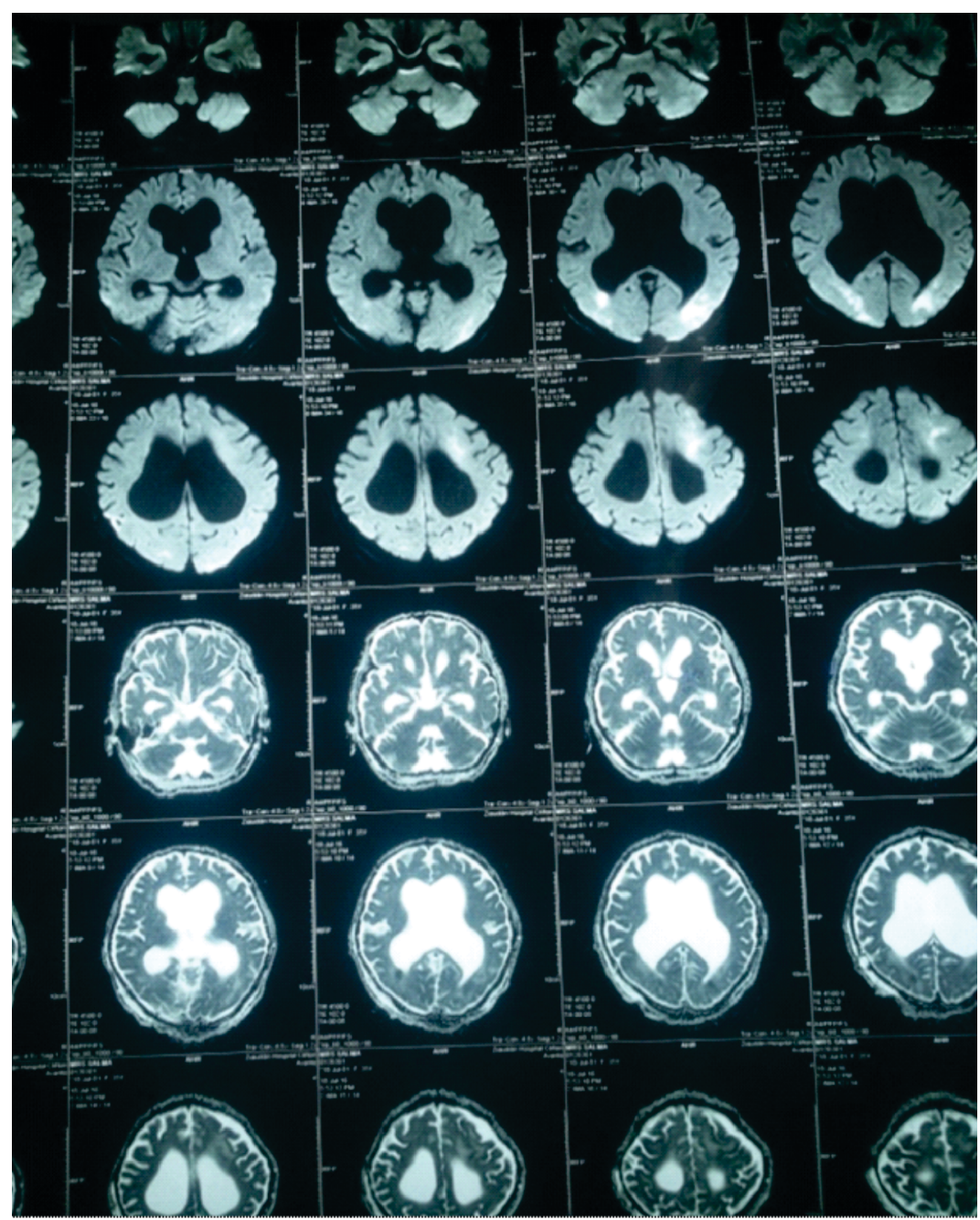

Figure Ia: Magnetic resonance imaging of brain performed on day three

cranial nerves were intact, no neck rigidity was found, and power was $5 / 5$ in all four limbs.

She was extubated 48 hours post neurosurgery and was shifted to the ward where she remained afebrile and vitally stable. She got discharged on day twelve. Regular physiotherapy was performed at home. She continued her follow up visits in outpatient department (OPD) for 3 months and fully recovered.

\section{DISCUSSION}

The pathogenesis of PRES remains poorly understood. Widely accepted theory is; dysfunction of endothelium and inability of the brain circulation to auto regulate, in response to acute hypertension. Vasogenic edema occurs due to hyper perfusion and disruption of the blood brain barrier. When unrecognized, irreversible cytotoxic edema may occur. ${ }^{2}$ PRES cases in normotensive patients have also been reported. Hydrocephalus is a rare complication of PRES, which is secondary to cerebrospinal fluid (CSF) circulation obstruction, acute hemorrhage and massive posterior fossa edema. Symptoms of PRES and eclampsia mimic but PRES can also develop in the postpartum period without a seizure ${ }^{2,3}$ and is found to be common in primigravidas and younger age group. Patients who develop late postpartum eclampsia should be highly suspected for PRES because it can occur between 48 hours to I month after an uneventful pregnancy. Guidelines for proper management of acute intrapartum or postpartum hydrocephalous and PRES are not defined. Prompt management of PRES is essential to avoid the risk of irreversible lesions. If timely recognized and treated, the clinical syndrome usually resolves completely within a week. ${ }^{4}$ Cerebral imaging is not indicated in uncomplicated cases of preeclampsia/eclampsia. When a suspicion of PRES is made, MRI is the gold standard because CT (computed tomography) scan reveals only $50 \%$ of the lesions. ${ }^{5}$ Treatment of PRES is quite similar to eclampsia and includes withdrawing the triggering factor. After delivery of the baby; antihypertensive drugs, especially labetalol, nifedipine and magnesium therapy, should be initiated, magnesium sulphate infusion can prevent convulsions, reduce cerebral edema and decrease maternal mortality with an improved infant outcome. Rapid reduction of blood pressure by more than 15\%-25\% can worsen cytotoxic edema and compromise utero-placental perfusion. The use of thiopental, valproate, or phenytoin was reported only for status epilepticus or multiple seizures and not for isolated seizures. ${ }^{4}$ Angiotensin converting enzyme inhibitors and angiotensin receptor blockers are contraindicated in pregnancy. If complete recovery of level of consciousness is not achieved then general measures like airway placement, invasive ventilation and anticonvulsant agents can be considered. ${ }^{3}$ The most recommended drug is IV lorazepam. Different types of shunts were tried in past for hydrocephalous management. Data illustrates that VA or VPL shunt should be replaced with a VP shunt in pregnant patients with pre existing hydrocephalous so it is least affected by the increased abdominal pressure. ${ }^{6}$ Spontaneous vaginal should be the mode of delivery in patients with newly diagnosed hydrocephalous/ shunt placement; but the second stage of labor, which may raise ICP due to intense straining, must be made brief. If an indication arises for caesarean section then it can be conducted under general anesthesia or epidural depending upon CSF status. Prophylactic antibiotic use in patients with CSF shunts after SVD or C/S is a debatable topic. This case report represents a list of challenges faced by obstetricians while dealing with difficult scenarios.

\section{CONCLUSION}

Significant overlap exists in clinical symptoms of hypertensive disorders in peri-partum period. PRES should be rendered as an important cause to consider when there is visual loss even in the absence of seizures in a pre-eclamptic 


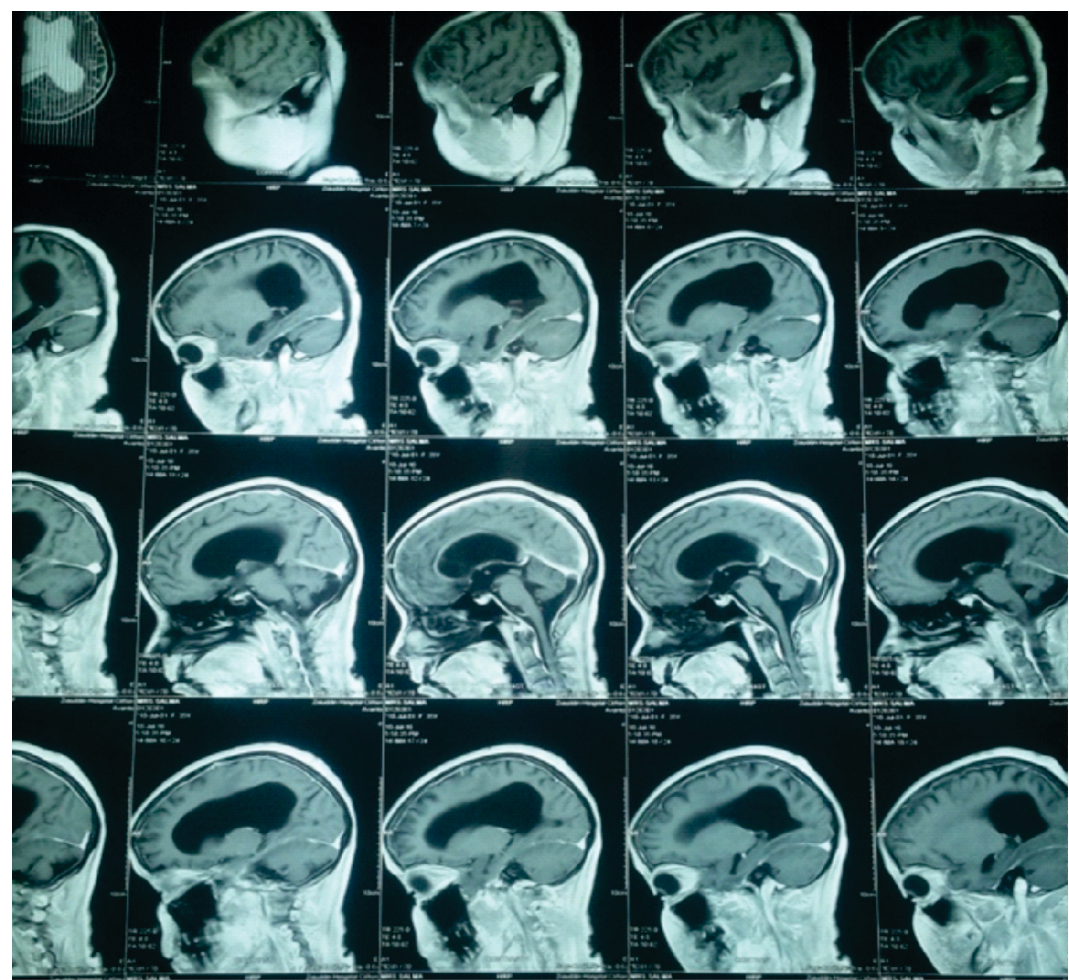

Figure Ib: Magnetic resonance imaging of brain performed on day three

patient. Cerebral imaging and rare conditions must be considered in patients who remain unresponsive to conventional management to avoid morbidity and mortality.

\section{REFERENCES}

I. Hossain N, Khan N, Panhwar N, Noureen S. Clinical spectrum of posterior reversible encephalopathy syndrome (PRES) in patients with eclampsia. Pak J Med Sci 2015;3I(5):

| | 2 | - 3. D O I:

10.12669/pjms.315.7707.

2. Ural UM, Balik G, ŞentürkS, Üstüner I, Çobanoğlu U, Şahin FK. Posterior reversible encephalopathy syndrome in a postpartum preeclamptic woman without seizure. Case Rep Obstet Gynecol 2014;2014:657903. DOI: I0.1|55/20|4/657903.

3. Pedraza R, Marik PE, Varon J. Posterior Reversible Encephalopathy Syndrome: A Review. Crit Care Shock 2009; | 2: | 35-43.

4. Poma S, Delmonte MP, Gigliuto C, Imberti R, Delmonte M, Arossa A, et al. Management of posterior reversible syndrome in preeclamptic women. Case Rep Obstet Gynecol 20।4;20।4: 928079 . DOI: $10.1155 / 2014 / 928079$

5. Nielsen LH, Grøn BS, Ovesen PG. Posterior reversible encephalopathy syndrome postpartum. Clin Case Rep 20I5;3(4):266-70. DOI: I0.1002/ ccr3.218.

6. Murakami M, Morine M, Iwasa T, Takahashi Y, Miyamoto T, Hon PK, et al. Management of maternal hydrocephalus requires replacement of ventriculoperitoneal shunt with ventriculoatrial shunt: $A$ case report. A rch Gynecol Obstet $2010 ; 282(3): 339-42$. DOI:

\section{AUTHORS' CONTRIBUTIONS}

Following authors have made substantial contributions to the manuscript as under:

AKJ: Identification \& diagnosis of the case, drafting the manuscript, final approval of the version to be published.

SA: Management of the case, critical review, final approval of the version to be published.

Authors agree to be accountable for all aspects of the work in ensuring that questions related to the accuracy or integrity of any part of the work are appropriately investigated and resolved.

CONFLICT OF INTEREST
Authors declared no conflict of interest
GRANT SUPPORT AND FINANCIAL DISCLOSURE
NIL

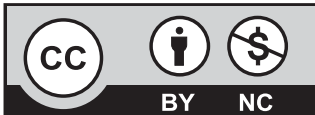

This is an Open Access article distributed under the terms of the Creative Commons Attribution-Non Commercial 2.0 Generic License.

KMUJ web address: www.kmuj.kmu.edu.pk

Email address: kmuj@kmu.edu.pk 